\title{
Evaluation of the MERIS aerosol product over land with AERONET
}

\author{
J. Vidot ${ }^{1}$, R. Santer ${ }^{2}$, and O. Aznay ${ }^{2}$ \\ ${ }^{1}$ Laboratoire de Météorologie Physique (LaMP), Observatoire de Physique du Globe de Clermont-Ferrand, Université Blaise \\ Pascal, Clermont-Ferrand, France \\ ${ }^{2}$ Laboratoire Interdisciplinaire des Sciences de l'Environnement, Maison de la Recherche en Environnement Naturel, \\ Université du Littoral Cote d'Opale, Wimereux, France
}

Received: 12 October 2007 - Published in Atmos. Chem. Phys. Discuss.: 25 February 2008

Revised: 17 September 2008 - Accepted: 26 November 2008 - Published: 17 December 2008

\begin{abstract}
The Medium Resolution Imaging Spectrometer (MERIS) launched in February 2002 on-board the ENVISAT spacecraft is making global observations of top-ofatmosphere (TOA) radiances. Aerosol optical properties are retrieved over land using Look-Up Table (LUT) based algorithm and surface reflectances in the blue and the red spectral regions. We compared instantaneous aerosol optical thicknesses retrieved by MERIS in the blue and the red at locations containing sites within the Aerosol Robotic Network (AERONET). Between 2002 and 2005, a set of 500 MERIS images were used in this study. The result shows that, over land, MERIS aerosol optical thicknesses are well retrieved in the blue and poorly retrieved in the red, leading to an underestimation of the Angstrom coefficient. Correlations are improved by applying a simple criterion to avoid scenes probably contaminated by thin clouds. To investigate the weakness of the MERIS algorithm, ground-based radiometer measurements have been used in order to retrieve new aerosol models, based on their Inherent Optical Properties (IOP). These new aerosol models slightly improve the correlation, but the main problem of the MERIS aerosol product over land can be attributed to the surface reflectance model in the red.
\end{abstract}

\section{Introduction}

There is a clearly need for an accurate representation of the distribution of aerosols over the globe not only because of their direct and indirect radiative impacts on climate (IPCC, 2007), but also because of their health impact on population (Wilson and Sprengler, 1996). The representation of the aerosols optical properties distribution is provided by several tools, from satellite aerosols products (Kaufman et

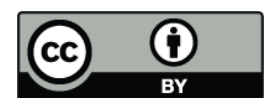

Correspondence to: J. Vidot (J.Vidot@opgc.univ-bpclermont.fr) al., 2002), surface measurements (Dubovik et al., 2002) and aerosol transport model (Chin et al., 2002). Information about aerosol absorption is often needed for radiative impact purposes, but it is still difficult to accurately obtain this quantity at global scales with current space sensors (Mishchenko et al., 2004). From space, actual retrievals on aerosol optical properties are mainly based on three different techniques: (i) from multi-bands unpolarized measurements, (ii) with polarization and/or (iii) multidirectionnality. All of these different techniques provide advantages/inconveniences on the aerosol retrieval. For example, multi-bands unpolarized sensors like the Moderate Resolution Imaging Spectroradiometer (MODIS) sensor allow a good spatial resolution at the ground but can provide information on total column amount and size of aerosols (Remer et al., 2005). The aerosol parameters have been recently improved with the MODIS Second Generation Algorithm (Levy et al., 2007) and the "DeepBlue" algorithm (Hsu et al., 2006). These new algorithms enhanced the possibility to discriminate dust particles from fine aerosols. Using the multidirectionnality as the Multiangle Imaging Spectroradiometer (MISR) sensor, provide constraints on the surface reflectance and on scattering properties of aerosols (Abdou et al., 2005). Adding the polarized measurements like POLDER increases the information content and provides constraints on the surface reflectance and on the fine mode of the aerosol distribution (Deuzé et al., 2001).

The Medium Resolution Imaging Spectrometer (MERIS) instrument can also assume an integral role in the effort of obtaining a global picture of aerosols due to its frequent global measurements of aerosol amount and type over a wide variety of surface types. The primary goal of MERIS is the ocean color observation, while the secondary purpose is the observation of the atmosphere and the terrestrial surface. MERIS is one of the instruments of the ENVISAT satellite launched in 2002. ENVISAT is a sun-synchronous orbit with an equator crossing time of 10:00 a.m. local time. MERIS is a programmable, medium-spectral resolution,

Published by Copernicus Publications on behalf of the European Geosciences Union. 
Table 1. Biome number, model name, associated AERONET site names and Principal Investigator (PI) with range of $\tau_{a}$ at $440 \mathrm{~nm}$ and Angstrom coefficient $\alpha$ over the number of match-ups $N$.

\begin{tabular}{|c|c|c|c|c|c|c|}
\hline Biome & Model name & AERONET sites & PI & $\tau_{a}(440)$ range & $\alpha$ range & $N$ \\
\hline \multirow{3}{*}{0} & \multirow{3}{*}{ Boreal America } & Bonanza Creek & J. Hollingsworth & $0.06-1.96$ & $0.6-1.9$ & 33 \\
\hline & & Bratts Lake & B. McArthur & $0.05-0.58$ & $1.1-2.0$ & 29 \\
\hline & & Pickle Lake & B. McArthur & $0.04-0.21$ & $1.3-1.8$ & 5 \\
\hline \multirow{2}{*}{1} & \multirow{2}{*}{ Boreal Euroasia } & Andenes & B. Holben & $0.07-0.31$ & $1.3-1.9$ & 3 \\
\hline & & Yakutsk & M. Panchenko & $0.07-0.26$ & $0.6-2.2$ & 8 \\
\hline 2 & MidLat West America & Rimrock & B. Holben & $0.14-0.79$ & $1.7-2.0$ & 4 \\
\hline \multirow{3}{*}{3} & \multirow{3}{*}{ MidLat East America } & GSFC & B. Holben & $0.03-1.23$ & $0.9-2.3$ & 59 \\
\hline & & Bondville & B. Holben & $0.06-1.41$ & $0.4-2.1$ & 32 \\
\hline & & Walker Branch & B. Holben & $0.06-0.70$ & $1.0-2.3$ & 23 \\
\hline \multirow{3}{*}{4} & \multirow{3}{*}{ MidLat Europe } & Minsk & A. Chaikovsky & $0.08-1.47$ & $0.9-1.9$ & 23 \\
\hline & & Lille & P. Goloub & $0.07-0.89$ & $0.3-1.8$ & 37 \\
\hline & & Ispra & G. Zibordi & $0.02-1.12$ & $0.6-3.4$ & 87 \\
\hline \multirow{2}{*}{5} & \multirow{2}{*}{ MidLat Asia } & Beijing & H.-B. Chen & $0.13-2.96$ & $0.7-1.5$ & 29 \\
\hline & & Tomsk & M. Panchenko & $0.09-0.39$ & $1.6-2.0$ & 12 \\
\hline 6 & Tropical America & Tenosique & M. J. Montero-Martinez & $0.1-2.22$ & $0.9-2.0$ & 19 \\
\hline \multirow{2}{*}{7} & \multirow{2}{*}{ Tropical Asia } & Bac Giang & H. Vet Le & $0.34-1.4$ & $0.9-1.6$ & 11 \\
\hline & & Pimai & B. Holben & 0.35 & 0.3 & 1 \\
\hline \multirow{3}{*}{8} & \multirow{3}{*}{ Equatorial America } & Alta Floresta & B. Holben & $0.05-1.26$ & $0.4-2.1$ & 48 \\
\hline & & Campo Grande Sonda & E. B. Pereira & $0.05-0.31$ & $0.7-2.0$ & 6 \\
\hline & & Belterra & B. Holben & $0.08-0.34$ & $0.7-1.4$ & 8 \\
\hline \multirow{3}{*}{9} & \multirow{3}{*}{ Equatorial Africa } & Mongu & B. Holben & $0.04-0.31$ & $0.9-2.7$ & 18 \\
\hline & & Ilorin & R. T. Pinker & 0.59 & 0.7 & 1 \\
\hline & & Djougou & P. Goloub & $0.28-0.5$ & $0.4-1.2$ & 3 \\
\hline 10 & Equatorial Asia & Jabiru & R. Mitchell & $0.08-0.24$ & $0.2-1.0$ & 6 \\
\hline
\end{tabular}

imaging spectrometer operating in the solar reflective spectral range. Fifteen spectral bands can be selected by ground command, each of which has a programmable width and a programmable location in the $390 \mathrm{~nm}$ to $1040 \mathrm{~nm}$ spectral range. The instrument's $68.5^{\circ}$ field of view around nadir covers a swath width of $1150 \mathrm{~km}$ with a spatial resolution of $1.2 \mathrm{~km}$ at nadir (Rast et al., 1999). The MERIS accuracy is $\pm 4 \%$ in reflectance (Delwart et al., 2003). The absolute uncertainties of the vicarious calibration of MERIS over land are found between 3 and 7\%, depending on the accuracies of the available ground truth data (Kneubuehler et al., 2004).

In this article, we evaluate the MERIS aerosol product over land. The first part will be devoted to the presentation of the general aspects of the aerosol retrieval over land from multi-channel sensors working in visible (VIS) to near infrared (NIR) spectral regions. Both 1st and 2nd MERIS processing are described. The second part presents the worldwide ground-based aerosol measurement Aerosol Robotic Network (AERONET) sites that we used in the evaluation of the MERIS aerosol product over land. The third section will compare the MERIS aerosol product over land against AERONET outputs, then describes a new aerosol models family based on AERONET sky radiances measurements. The new aerosol model family obtains Inherent Optical Properties of aerosols (IOPA) that slightly improved the MERIS aerosol product over land. Lastly, we will point out the weakness of the surface reflectance that explains the poor MERIS aerosol product over land in the red.

\section{MERIS aerosol retrieval}

2.1 Generality of the MERIS aerosol remote sensing over land

Aerosol remote sensing over land from space is a very difficult task because of the high reflectivity of the Earth compared to the aerosol scattering signal in the back-scattering region. The technique chosen for MERIS (Santer et al., 


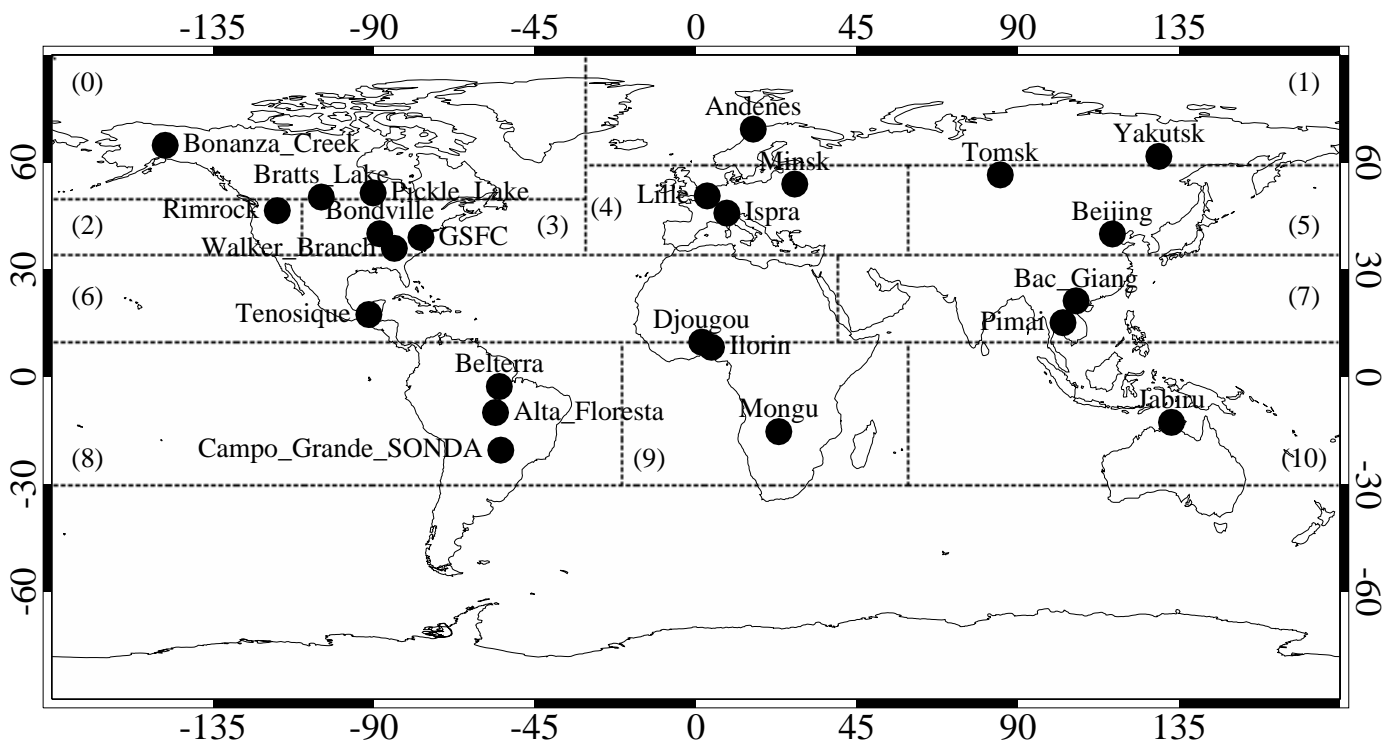

Fig. 1. Geographical distribution of the 24 AERONET sites used in this study. Biomes are represented by dashed boxes with associated numbers given between brackets.

1999) relies on the well known Dense Dark Vegetation (DDV, Kaufman and Sendra, 1988) concept, generalized to the dark target concept of MODIS (Kaufman et al., 1997). The idea here is to detect dark and stable targets whose reflectivity is know accurately with a simple and reliable method. For MERIS, the Atmospherically Resistant Vegetation Index (ARVI, Kaufman and Tanré, 1992) is used to detect DDV. ARVI is defined by

$\mathrm{ARVI}=\frac{\rho_{a g}^{865}-\left(\rho_{a g}^{670}-\gamma\left(\rho_{a g}^{443}-\rho_{a g}^{670}\right)\right)}{\rho_{a g}^{865}+\left(\rho_{a g}^{670}-\gamma\left(\rho_{a g}^{443}-\rho_{a g}^{670}\right)\right)}$,

where $\rho_{a g}$ is the reflectance at $865 \mathrm{~nm}, 670 \mathrm{~nm}$ or $443 \mathrm{~nm}$, corrected from gaseous absorption and Rayleigh scattering. $\gamma$ is a coefficient fixed to 1.3 for DDV (Santer et al., 1999). ARVI allows obtaining a relation between NIR band (at $865 \mathrm{~nm}$ where aerosols contribution is low) and red and blue bands (at $670 \mathrm{~nm}$ and $443 \mathrm{~nm}$ respectively, where surface contributions are low). By comparison, the MODIS team uses the capability to observe in the near infrared at $2.1 \mu \mathrm{m}$ for detecting dark targets. In all of these techniques, the two main sources of uncertainties are the accuracy of the reflectance model of the target and the accuracy of the aerosol models, which were used for the computation of the aerosol scattering functions.

\subsection{The aerosol retrieval in the 1st MERIS processing}

In the case of MERIS, 11 biomes have been chosen to represent the spatial and the temporal variations of the DDV concept over the globe. Figure 1 gives the geographical distribution of the 11 biomes (represented by dashed boxes with the number in brackets, from 0 to 10). Table 1 provides the model name of each biome. For each biome a set of Look Up Tables (LUT) has been generated that gives the DDV Bidirectional Reflectance Function (BRDF) in the three bands (blue, red and NIR) and the coupling terms between the DDV and the atmosphere (Ramon and Santer, 2001). The aerosol characterization is based on aerosol models. They are defined by a size distribution $n(R)$ of particles of radius $R$ represented by the Junge power law, $n(R) \approx R^{-(\alpha+3)}$, and by 26 values of the Angstrom coefficient $\alpha_{J}$ (from 0 to 2.5 by step of 0.1). These models will be called Junge models hereafter. They are also defined by 3 values for the real part of the refractive index $m(1.33,1.44$ and 1.55). No absorption has been included in the aerosol models. At the present time, the aerosol refractive index is set to 1.44 by default, which corresponds to a standard continental aerosol model. The aerosol optical properties (extinction coefficient, single scattering albedo and phase function) have been precalculated at $550 \mathrm{~nm}$ with the Mie theory. Aerosol optical thicknesses (AOTs) $\tau_{a}$ in the red and in the blue are retrieved for each Angstrom coefficient $\alpha_{J}$. The model for which the Angstrom coefficient is the closest to the one that is obtained from the $\tau_{a}$ retrieval is the model that we select. The aerosol product of the 1st MERIS processing consists of $\tau_{a}$ at $865 \mathrm{~nm}$ and $\alpha$.

\subsection{The aerosol retrieval in the 2nd MERIS processing}

Because the concept of DDV was too restrictive in order to get a good spatial representation of the aerosols, the model of the surface reflectance has been extended to brighter surfaces called Land Aerosol Remote Sensing (LARS). The LARS surface reflectances in the blue and in the red that have a linear dependence with the ARVI (Santer et al., 2007a), can 


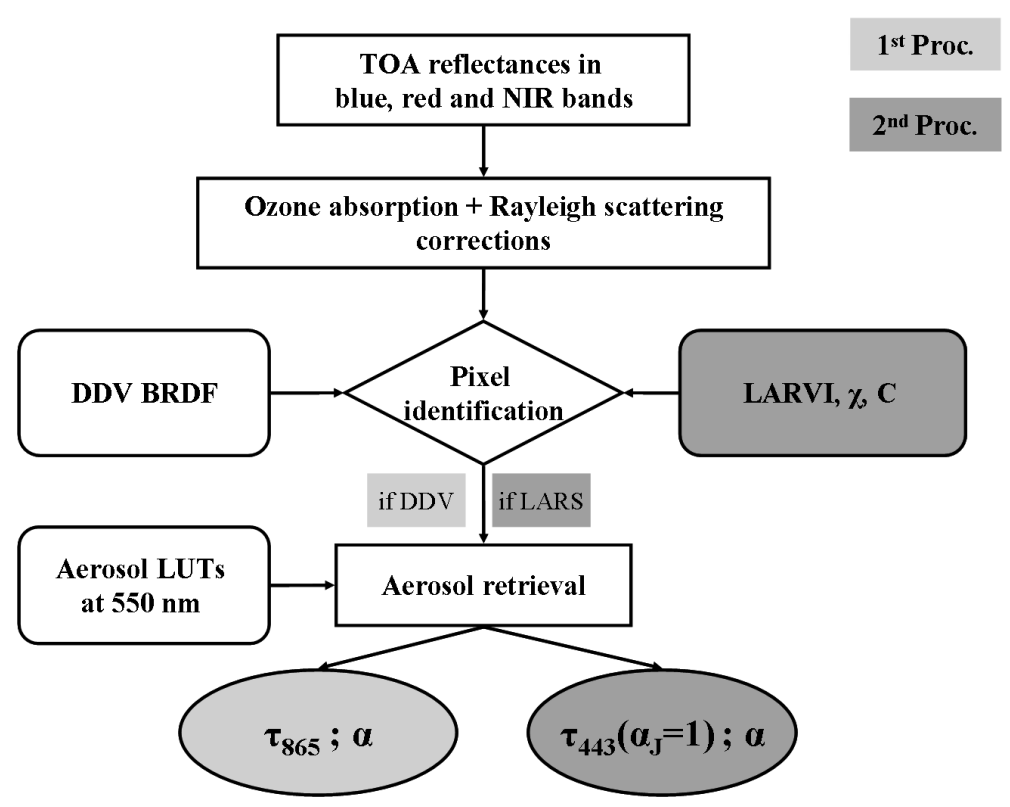

Fig. 2. Flowchart of the MERIS aerosol retrieval over land. Grey boxes show the change between the 1 st processing and the 2 nd processing.

be written as

$$
\begin{gathered}
\rho_{\mathrm{LARS}}\left(m, \lambda, \theta_{v}, \theta_{s}, \phi_{v}-\phi_{s}\right)=C(m) \rho_{\mathrm{DDV}}\left(\lambda, \theta_{v}, \theta_{s}, \phi_{v}\right. \\
\left.-\phi_{s}\right)(1+\chi(\lambda, m)(\mathrm{LARVI}-\mathrm{ARVI})),
\end{gathered}
$$

and depends on the month $(m)$, the wavelength $(\lambda)$, the viewing zenith angle $\left(\theta_{v}\right)$, the solar zenith angle $\left(\theta_{s}\right)$, and the azimuth angle difference between viewing and solar $\left(\Phi_{v}-\Phi_{s}\right)$. Further details of the estimation of the monthly coefficients $(C)$, the slopes of the linear dependency $\chi$ and the lower values of the ARVI (LARVI) where the linear dependence is valid, can be found in Santer et al. (2007a).

The aerosol product from the 2nd MERIS processing offers a much better spatial coverage but also introduces more errors in the $\tau_{a}$ and $\alpha$ retrievals. These errors occur mostly in the red, as the variation of the surface reflectance with the ARVI is more pronounced than in the blue and therefore most subject to uncertainties. Preliminary tests of the aerosol retrieval using the LARS indicated a large and random spatial distribution of $\alpha$ rending suspect the retrieval of $\tau_{a}$ in the red. Efforts were made to improve the characterization of the surface reflectance in the blue and in the red using the MODIS level 3 albedo maps (Moody et al., 2003) to produce the required surface reflectance. Both the offset and slope of the linear dependence with the ARVI, in a $1^{\circ}$ by $1^{\circ}$ spatial grid, have been defined (Ramon and Santer, 2005). The initial 11 biomes are kept in order to describe the BRDF of the LARS pixels. Nevertheless, $\alpha$ values were still suspicious. They are flagged because out of range values [0-2.5] on numerous occasions. Therefore, the following decisions were taken: (i) to output $\tau_{a}$ at $443 \mathrm{~nm}$ instead of $\tau_{a}$ at $865 \mathrm{~nm}$ because of the disastrous effect of $\alpha$; (ii) to produce the $\tau_{a}$ in the blue using the Junge model of $\alpha_{J}=1$ and (iii) to output $\alpha$ as an indicator of the aerosol type as it was computed for the 1st processing. Then, the aerosol product of the 2 nd MERIS processing consists of $\tau_{a}$ in the blue (at $443 \mathrm{~nm}$ ) and $\alpha$. Figure 2 provides the flowchart of both processings.

\section{AERONET data}

AERONET is a globally distributed network of automated ground-based instruments and data archive system, developed to support the aerosol community. The instruments used are CIMEL spectral radiometers that measure the spectral extinction of the direct Sun radiance (Holben et al., 1998). The aerosol optical depths are determined using the Beer-Bouguer Law in several spectral bands. For this study, level-2 data are used and consist of $\tau_{a}$ at $440 \mathrm{~nm}$ and $675 \mathrm{~nm}$, retrieved at least every $15 \mathrm{~min}$ during day time. Level-2 data are cloud-free and quality assured retrieved from pre- and post-field calibrated measurements (Smirnov et al., 2000). The estimated accuracy in the AERONET $\tau_{a}$ is between \pm 0.01 and \pm 0.02 and depends on the wavelength, for an airmass equal to 1 (Dubovik et al., 2000).

We selected geographically diverse AERONET sites that provided generally good-quality measurements records between 2002 and 2005. A total of 24 AERONET sites have been selected in order to cover the 11 biomes of MERIS and the range of possible aerosol optical thicknesses from clean areas to turbid ones (due to different air masses types and sources as biomass burning, continental and/or dusty conditions). Figure 1 gives the geographical distribution of AERONET sites (represented by black dots). We optimally selected three AERONET sites per biome. Unfortunately, 
biomes 2 (MidLat West America), biome 6 (Tropical America) and biome 10 (Equatorial Asia) are under represented with only one site because of the lack of AERONET sites, the lack of AERONET measurement or the area not covered by vegetations (mainly desert or snow-covered areas). Information about AERONET sites per biome (name and Principal Investigator of the site) are provided in Table 1 . We also gave the range of $\tau_{a}$ in the blue and the range of $\alpha$ over the number of match-ups $(N)$ that have been used in this study.

Biome 0 (Boreal America) is represented by three AERONET sites that cover $\tau_{a}$ in the blue from 0.04 to 1.96 and $\alpha$ between 0.6 and 1.9. The large value of $\alpha$ is representative of small particles. The artic atmosphere is generally clear but frequently subjected to forest fires in Alaska. Jet streams also transport pollution from Asia or other source regions into this region (Bokoyé et al., 2002). Biome 1 (Boreal Euroasia) is represented by two AERONET sites but suffers from a lack of match-ups $(N=11)$ and low variability of $\tau_{a}$ in the blue (from 0.07 to 0.31 ). Those regions can also be subjected by long range transport of artic haze (Toledano et al., 2006) or forest fires, that explains the high values of the $\alpha$ (up to 2.2). Biome 2 (Mid Latitude West America) is represented by only one AERONET site and few matchups $(N=4)$ where $\tau_{a}$ in the blue is between 0.14 and 0.79 . This part of North America can be affected by aerosols transported from Eurasia. Biome 3 (Mid Latitude West America) is represented by three AERONET sites with $\tau_{a}$ in the blue from 0.03 to 1.41 . Biome 4 (Mid Latitude Europe) is represented by three AERONET sites with $\tau_{a}$ in the blue from 0.02 to 1.47. AERONET sites of biomes 3 and 4 are continental sites that cover a diversity of urban and industrial pollution aerosols (Kahn et al., 2005). Biome 5 (Mid Latitude Asia) is represented by two AERONET sites with $\tau_{a}$ in the blue from 0.09 to 2.96. Due to combined influences of arid dust region production and increased fossil fuel usage, the East Asia regions often experience very high concentrations of tropospheric aerosols (Eck et al., 2005). Biome 6 (Tropical America) is represented by one AERONET site with $\tau_{a}$ in the blue from 0.1 to 2.22. The Mexico area is considered as a heavily urban polluted site. Biome 7 (Tropical Asia) is represented by two AERONET sites with $\tau_{a}$ in the blue from 0.34 to 1.4. Those different sites are industrialized urban area (Grey et al., 2006). Biome 8 (Equatorial America) is represented by three AERONET sites with $\tau_{a}$ in the blue from 0.05 to 1.26. The Amazonian Basin is a great source of biomass burning aerosol during the period from August to October (Schafer et al., 2002). Biome 9 (Equatorial Africa) is represented by three AERONET sites with $\tau_{a}$ in the blue from 0.04 to 0.59 . Africa is an important source of desert dust and biomass burning aerosols (Eck et al., 2001). Biome 10 (Equatorial Asia) is represented by one AERONET site with $\tau_{a}$ in the blue from 0.08 to 0.24 .

The different sites we selected will give us a good picture of the quality of the MERIS aerosol optical depths over land. However, for some biomes, we do not expect to make any conclusion on the quality of the MERIS aerosol retrieval due to the lack of match-ups (such as biomes 2 and 10) but we kept them for the global comparison nevertheless.

\section{The results}

\subsection{Initial validation}

In order to take into account both the spatial and temporal variability of aerosol distribution, the MERIS level-2 aerosol product at $1.2 \mathrm{~km}$ pixel resolution and the AERONET direct Sun measurements need to be collocated in space and time. We required at least 2 out of possible 5 AERONET measurements within \pm 30 min of MERIS overpasses and at least $10 \%$ out of possible MERIS retrievals in a square box of $10 \times 10$ pixels centered over AERONET sites (that represent 10 measurements over a $12 \times 12 \mathrm{~km}^{2}$ area). The mean values of the collocated spatial and temporal ensemble are then used in linear regression and root mean square errors (rmse) analysis. The total number of match-ups we obtained was 500 for the 24 AERONET sites between 2002 and 2005. The left panel of Table 2 give an overview of the results between 2nd processing MERIS and AERONET $\tau_{a}$ in the blue. The number of match-ups $N$, the correlation coefficient $r$, the linear regression equation coefficients (slope and intercept) and the rmse are provided for each biome. For biomes 1 and 10 , correlations are poor (with correlation coefficient of 0.23 and 0.37 , respectively) certainly due to a wrong surface reflectance model in these extreme areas. The correlation for biome 2 is perfect $(r=1)$ but biased by the few match-ups. For others biomes, correlations are good with at best $r=0.93$ for biome 0 . In most cases, slopes are greater than 1 , which implies an underestimation of the MERIS $\tau_{a}$ compared to the AERONET value. But in some cases, we are very close to the 1:1 line (for example, see biomes 0 and 4). Intercepts are small and rmse are comprises between 0.139 and 0.53 . The latter high value of rmse of 0.53 for biome 5 might be explained by an effect of absorption that is not taken into account in our aerosol models. One particular feature that we can observe in some cases is that MERIS shows a very large value of $\tau_{a}$ when compared to AERONET. This might be explained by the presence of thin clouds, like cirrus, that the actual MERIS algorithm is not able to flag. In order to remove these contaminated scenes, we applied a simple threshold on the standard deviation of $\tau_{a}$ in the blue within the box (called $\sigma$-filter hereafter). A value of 0.15 seems to be the best value (D. Ramon, personal communication) in order to remove inhomogeneous scene contaminated by thin clouds. We applied the $\sigma$-filter and in the right panel of Table 2, we provided the statistical outputs from the $\sigma$ filtered match-ups scatterplots. In most biomes, correlation coefficients slightly increased, rmse decreased without significantly changing neither the slope nor offset coefficients of the linear regression. However, the $\sigma$-filter is not the most 
Table 2. Results of the comparison between the 2nd processing MERIS $\tau_{a}$ and AERONET $\tau_{a}$ in the blue for each biome for the initial match-ups (unfiltered) and for the $\sigma$-filtered match-ups.

\begin{tabular}{|c|c|c|c|c|c|c|c|c|c|c|}
\hline \multirow[b]{2}{*}{ Biome } & \multicolumn{5}{|c|}{ Unfiltered } & \multicolumn{5}{|c|}{$\sigma$-filtered } \\
\hline & $N$ & $r$ & Slope & Intercept & rmse & $N$ & $r$ & Slope & Intercept & rmse \\
\hline 0 & 67 & 0.93 & 1.03 & -0.09 & 0.149 & 60 & 0.97 & 1.10 & -0.09 & 0.110 \\
\hline 1 & 11 & 0.23 & 0.22 & 0.07 & 0.204 & 3 & 0.98 & 1.34 & 0.18 & 0.088 \\
\hline 2 & 4 & 1.00 & 1.86 & -0.39 & 0.139 & 3 & 0.97 & 2.08 & -0.46 & 0.135 \\
\hline 3 & 114 & 0.89 & 1.34 & -0.11 & 0.147 & 104 & 0.90 & 1.38 & -0.11 & 0.141 \\
\hline 4 & 142 & 0.77 & 1.05 & -0.02 & 0.142 & 130 & 0.82 & 1.11 & -0.03 & 0.127 \\
\hline 5 & 41 & 0.62 & 0.82 & -0.09 & 0.530 & 32 & 0.61 & 0.85 & -0.12 & 0.550 \\
\hline 6 & 19 & 0.98 & 1.41 & -0.18 & 0.187 & 19 & 0.98 & 1.41 & 0.18 & 0.187 \\
\hline 7 & 12 & 0.83 & 1.36 & -0.12 & 0.242 & 12 & 0.83 & 1.36 & -0.12 & 0.242 \\
\hline 8 & 62 & 0.89 & 1.11 & -0.12 & 0.184 & 54 & 0.93 & 1.18 & -0.12 & 0.155 \\
\hline 9 & 22 & 0.59 & 0.6 & 0.05 & 0.135 & 20 & 0.70 & 0.87 & -0.01 & 0.109 \\
\hline 10 & 6 & 0.37 & 0.13 & 0.12 & 0.250 & 4 & 0.98 & 0.47 & 0.05 & 0.120 \\
\hline
\end{tabular}

Table 3. Results of the comparison between the 2nd processing MERIS $\tau_{a}$ and AERONET $\tau_{a}$ in the red for each biome for the initial match-ups (unfiltered) and for the $\sigma$-filtered match-ups.

\begin{tabular}{crrrrr|rrrrr}
\hline & \multicolumn{5}{c|}{ Unfiltered } & \multicolumn{5}{c}{$\sigma$-filtered } \\
biome & $N$ & $r$ & Slope & Intercept & rmse & $N$ & $r$ & Slope & Intercept & rmse \\
\hline 0 & 67 & 0.90 & 0.76 & -0.06 & 0.166 & 60 & 0.94 & 0.83 & -0.07 & 0.138 \\
1 & 11 & 0.09 & 0.05 & 0.06 & 0.222 & 3 & 1.00 & 0.88 & -0.12 & 0.147 \\
2 & 4 & 1.00 & 0.77 & -0.14 & 0.230 & 3 & 0.97 & 1.50 & -0.35 & 0.206 \\
3 & 114 & 0.74 & 0.86 & -0.04 & 0.127 & 104 & 0.76 & 0.91 & -0.04 & 0.117 \\
4 & 142 & 0.60 & 0.59 & 0.02 & 0.134 & 130 & 0.64 & 0.65 & 0.01 & 0.120 \\
5 & 41 & 0.57 & 0.48 & -0.01 & 0.532 & 32 & 0.55 & 0.50 & -0.03 & 0.523 \\
6 & 19 & 0.94 & 1.00 & -0.11 & 0.147 & 19 & 0.94 & 1.00 & -0.11 & 0.147 \\
7 & 12 & 0.78 & 1.04 & -0.12 & 0.167 & 12 & 0.78 & 1.04 & -0.12 & 0.167 \\
8 & 62 & 0.86 & 0.60 & -0.04 & 0.227 & 54 & 0.89 & 0.62 & -0.03 & 0.206 \\
9 & 22 & 0.32 & 0.27 & 0.05 & 0.182 & 20 & 0.46 & 0.50 & 0.01 & 0.145 \\
10 & 6 & 0.41 & 0.14 & 0.08 & 0.250 & 4 & 0.97 & 0.44 & 0.03 & 0.138 \\
\hline
\end{tabular}

efficient test to remove high thin cirrus because (i) they can be very homogeneous over the scene and (ii), they may have an optical thickness lower or near the same order of magnitude as aerosols'. In order to minimize the effect of high, thin cirrus clouds, oxygen pressure can be utilized as an effective mask. Indeed, MERIS offers the possibility to accurately retrieve the cloud top pressure thanks to its window and absorption dual channels in the $\mathrm{O}_{2}$ A-band (Preusker and Fischer, 1999). The use of the cloud top pressure retrieval is even able to mask very thin cirrus clouds (Ramon et al., 2002). Unfortunately, we did not use the cloud top pressure based mask in our study.

The same comparison has been done in the red. Table 3 provides the summary of statistical outputs from the scatterplots both with and without the $\sigma$-filter (i.e., the threshold on the standard deviation of $\tau_{a}$ in the blue). Main conclusions of the comparison are that MERIS overestimates $\tau_{a}$ compared to AERONET, and the correlations are reduced in most of the cases in the red than in the blue. In the red, the application of the filter allows us to improve correlations.

In order to summarize the comparison, we combine all the data irregardless of their location. Figure 3 indicates the quality of the MERIS retrieval in the blue from the 2nd processing without (Fig. 3a) and with (Fig. 3b) the $\sigma$-filter. Correlations in the blue are very good with $r=0.8$ and a linear regression close to the $1: 1$ line (slopes of 0.98 and small negative intercept of -0.03 ). The $\sigma$-filter allows to slightly increase the correlation coefficient to 0.83 and to reduce the rmse from 0.215 to 0.2 . Figure 4 indicates the quality of the MERIS retrieval in the red from the 2 nd processing without (Fig. 4a) and with (Fig. 4b) the $\sigma$-filter. Overall, the MERIS $\tau_{a}$ retrieval in the red is not as good as the retrieval in the blue, as $r=0.7$ (increased to 0.73 with the $\sigma$-filter) and with the slope of the regression of 0.57 (increased to 0.62 with 
(a)

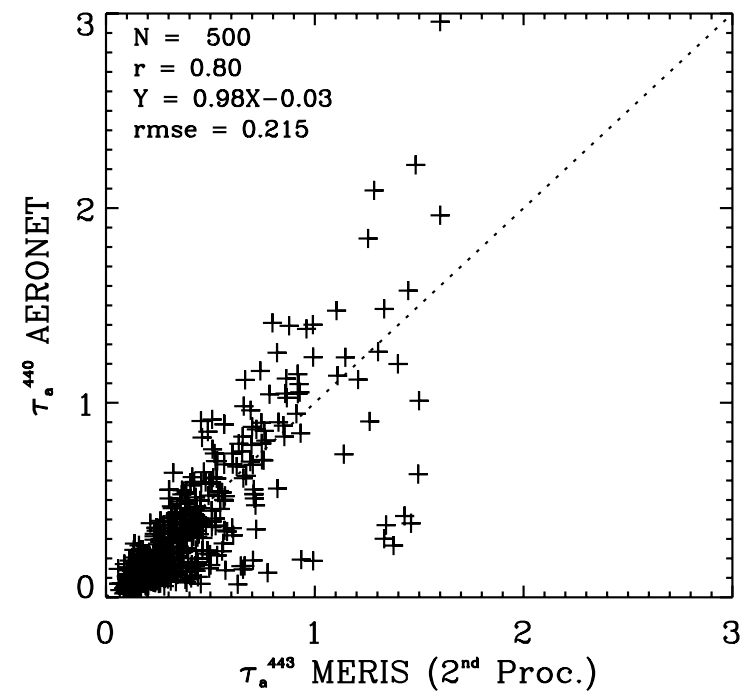

(b)

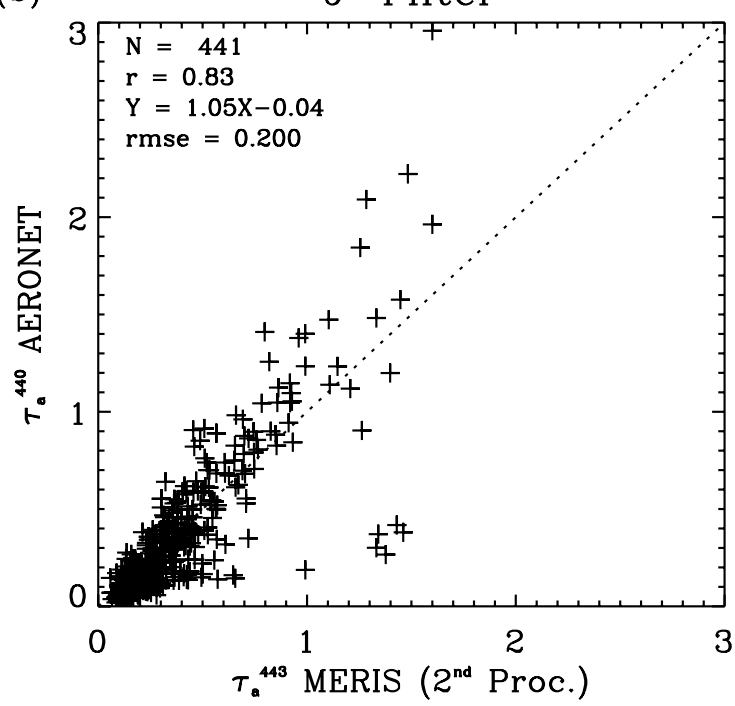

Fig. 3. Scatterplot of $\tau_{a}$ AERONET versus 2nd processing $\tau_{a}$ MERIS in the blue for the initial match-ups (a) and for the $\sigma$-filtered match-ups (b).

(a)

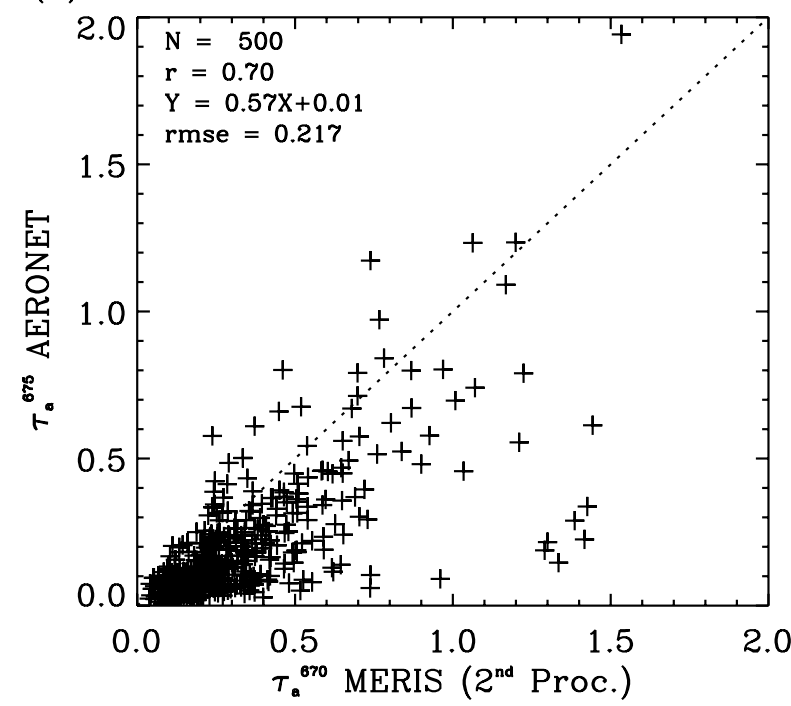

(b)

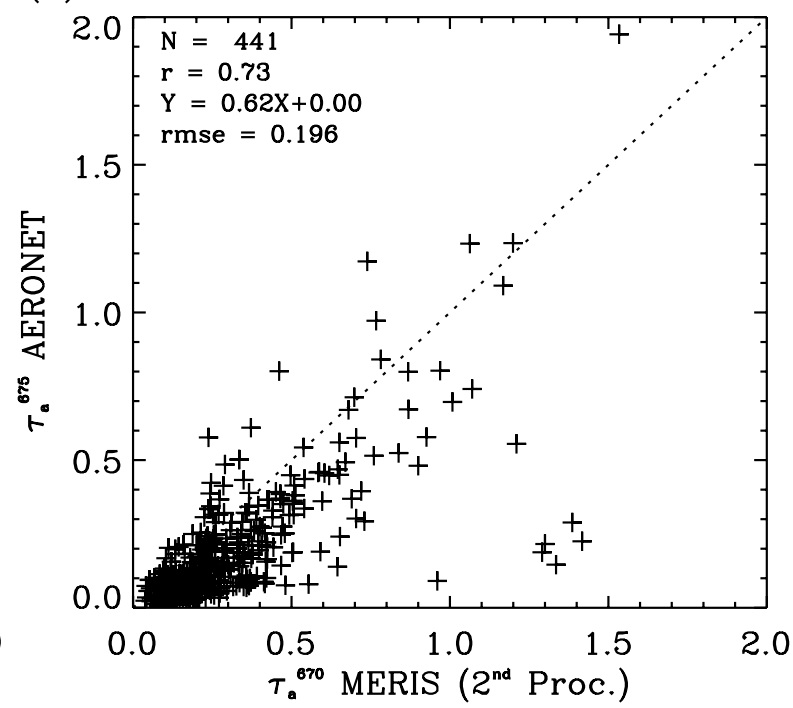

Fig. 4. Same as Fig. 3 for $\tau_{a}$ in the red.

the $\sigma$-filter). In Fig. 5, the similar comparison on $\alpha$ is shown and looks less favorable. In both cases (i.e., for match-ups selected with or without the $\sigma$-filter), MERIS shows larger aerosols than AERONET.

\subsection{Relevance of the 2nd MERIS processing approach}

At this stage, we have only presented the evaluation of the MERIS 2nd processing aerosol product over land. We can alter the Junge models in order to evaluate the 1 st processing. Actually, in the 2nd processing, it is partially the 1st processing in the combined retrieval of $\tau_{a}$ in the blue and in the red (or $\tau_{a}$ in the blue and $\alpha$ ). The main difference is that it is applied to LARS pixels in the 2nd processing, whereas it was applied to DDV pixels in the 1st processing. But $\alpha$ remains unchanged between the two processing on LARS pixels. 
(a)

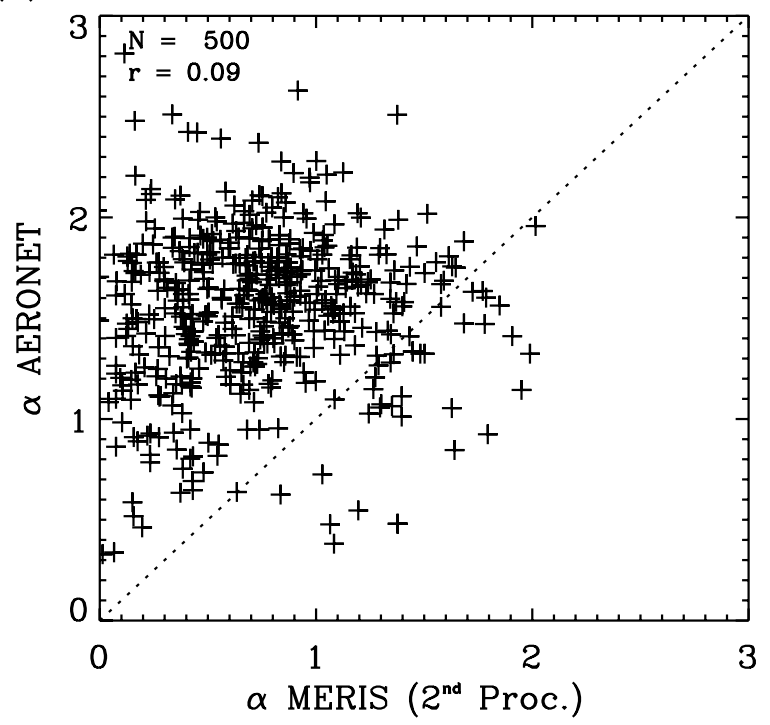

(b)

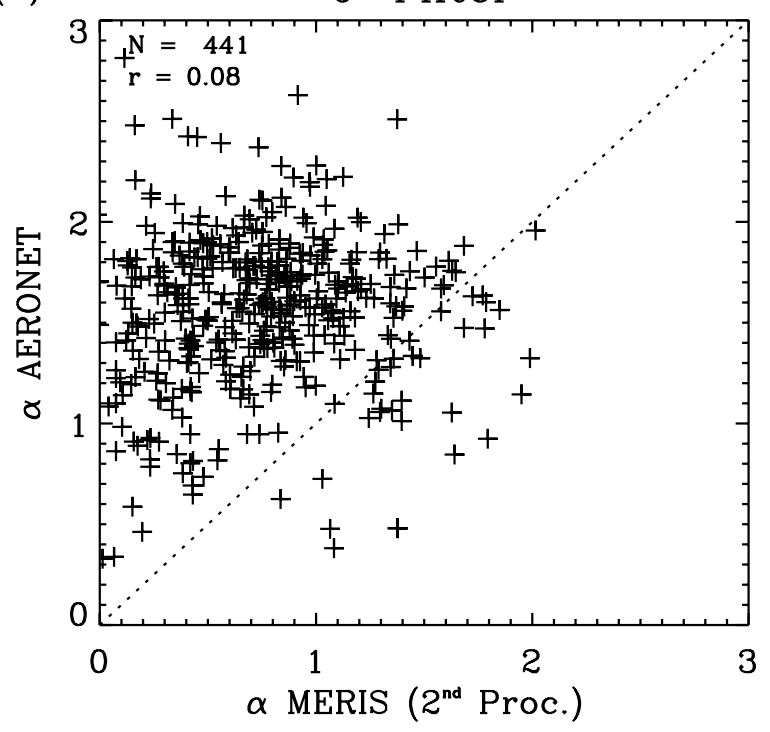

Fig. 5. Same as Fig. 3 for $\alpha$.

In the 1 st processing, $\alpha$ was used as the spectral dependence of $\tau_{a}$ in the retrieval of $\tau_{a}$ in the blue. Then to evaluate the 1 st processing, we have to recalculate $\tau_{a}$ from the 2nd processing aerosol product (i.e., $\tau_{a}$ and $\alpha_{J}=1$ ) by using the retrieved $\alpha$. Figure 6 gives the results of $\tau_{a}$ in the blue on the $\sigma$-filtered match-ups. Taking the retrieved $\alpha$ compared to $\alpha=1$ leads to a depreciated retrieval of the $\tau_{a}$ in the blue. The correlation coefficient decreased from 0.83 (2nd processing) to 0.72 (1st processing). The slope also decreased from 1.05 to 0.73 , respectively. The rmse increased by 0.071 .

In order to explain the depreciation, we have to introduce the relation between the aerosol path radiance $\left(L_{a}\right)$ that MERIS measures and the aerosol product $\tau_{a}$. In the pri-

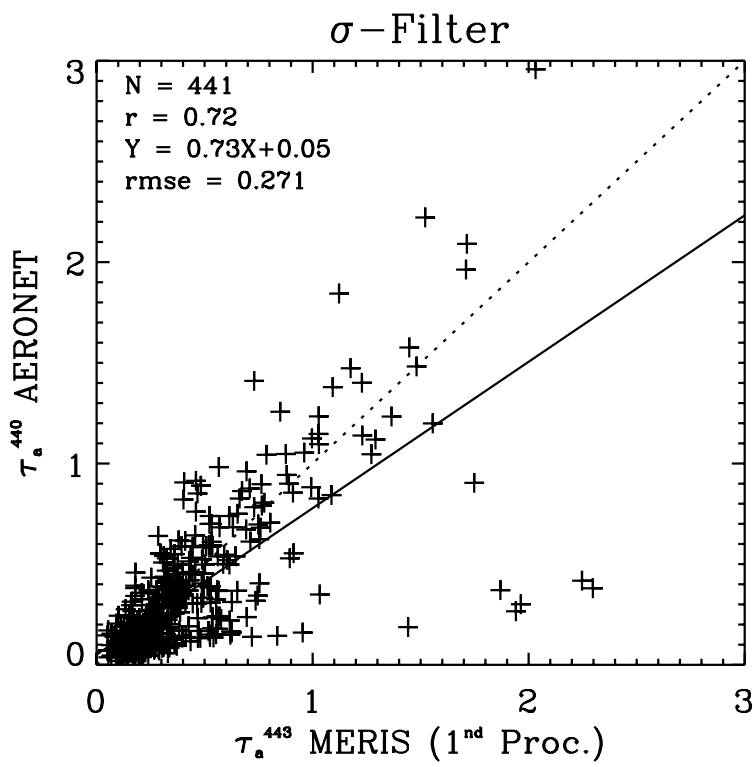

Fig. 6. Scatterplot of $\tau_{a}$ AERONET versus 1st processing $\tau_{a}$ MERIS in the blue for the $\sigma$-filtered match-ups.

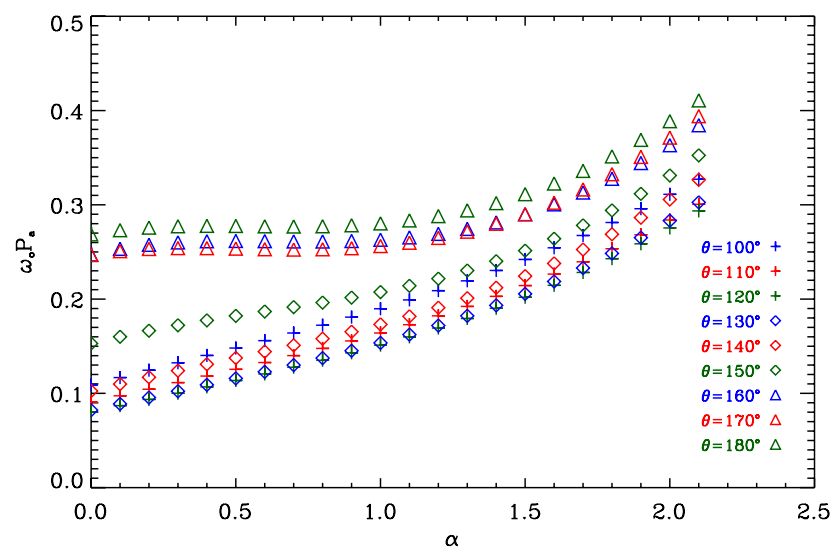

Fig. 7. The dependency of $\omega_{0} P_{a}$ versus $\alpha$ in the MERIS LUTs.

mary scattering approximation, the aerosol path radiance is expressed by:

$L_{a}^{0}=\frac{\tau_{a} \varpi_{0} P_{a}(\theta)}{4 \mu_{v}} \frac{E_{s}}{\pi}$,

where $E_{s}$ is the solar irradiance for the central wavelength of each spectral band corrected for the Sun-Earth distance, $\omega_{0}$ is the single scatting albedo, $P_{a}$ the aerosol phase function, $\theta$ the scattering angle and $\mu_{v}$ the cosine of the sensor viewing angle.

The depreciated retrievals can now be explained by two effects. First, the product $\omega_{0} P_{a}$ in the backscattering region (for MERIS $\theta$ is comprise between $100^{\circ}$ to $150^{\circ}$ ) increases with $\alpha$. Figure 7 show $\omega_{0} P_{a}$ versus $\alpha$ for different values of $\theta$. Secondly, MERIS underestimates $\alpha$ (see Fig. 5b); therefore MERIS underestimates $\omega_{0} P_{a}$ and overestimates $\tau_{a}$ in 
the blue. The decision to arbitrary set $\alpha=1$ for the MERIS 2nd processing is justified.

\subsection{Doing better with a new set of aerosol models?}

The interpretation of the aerosol path radiance into $\tau_{a}$ relies on the use of 26 Junge models. The ability for these aerosol models to describe the aerosol optical properties was reported by Ramon et al. (2003). This validation exercise was based on CIMEL AERONET measurement of the sky radiance in the principal plane. The following methodology, described by Santer and Lemire (2004), was used:

- $\alpha$ between $440 \mathrm{~nm}$ and $675 \mathrm{~nm}$ is used to select the two boundary Junge models,

- The Successive Order of Scattering (SOS, Deuzé et al., 1989) code is used to simulate the sky radiance in the principal plane,

- The inputs to the SOS code are the CIMEL $\tau_{a}$ at the time of the sky radiance measurements and with the corresponding geometrical conditions,

- Simulated and measured sky radiances are compared.

This evaluation of the Junge models led to noticeable discrepancies in the sky radiance retrieval. A similar approach highlights that the Junge models overestimated the sky radiance with a systematic bias of $10 \%$ at $675 \mathrm{~nm}$ and $30 \%$ at $870 \mathrm{~nm}$ (Aznay and Santer, 2007). The performance of the Junge models in the blue is a bit more difficult to conclude because of the predominance of the Rayleigh scattering.

An alternative use of the CIMEL sky radiance is to retrieve $\omega_{0} P_{a}$ (Santer and Martiny, 2003; Santer et al., 2007b). Therefore, the European Space Agency (EAS) undertook an action to produce a new set of aerosol models based on the interpretation of the CIMEL sky radiances to retrieve the inherent optical properties of aerosols, i.e. the product $\omega_{0} P_{a}$ (called IOPA models hereafter). This new set of aerosol models is still classified in $\alpha$ for values between 0 and 2.5 by step of 0.1. Results are reported in Zagolski et al. (2007) for a similar approach conducted over water. We shown in Fig. 8, the comparison of $\omega_{0} P_{a}$ for different $\alpha$ between the initial values using the Junge models and the IOPA models retrieved from AERONET. The agreement is sometimes excellent, mainly for values of $\alpha$ near 1 (Fig. 8c, d and e).

4.3.1 The MERIS 2nd processing with IOPA models: deriving $\tau_{a}$ in the blue

In the 2nd processing, the $\alpha=1$ Junge model is selected, so we do not expect to see spectacular changes on the retrieval of $\tau_{a}$ in the blue when replacing the Junge aerosol models by the IOPA models. In order to change the aerosol model, we can at first use the primary scattering approximation to describe the aerosol path radiance (Eq. 3). If we change $\omega_{0} P_{a}$, then we use a simple ratio technique to derive a new value of $\tau_{a}$, that is given by:

$\frac{\tau_{a}^{\mathrm{IOPA}}}{\tau_{a}^{\text {Junge }}}=\frac{\left[\varpi_{0} P_{a}(\theta)\right]_{\mathrm{Junge}}}{\left[\varpi_{0} P_{a}(\theta)\right]_{\mathrm{IOPA}}}$.

But if we modify $\tau_{a}$, then we have to take into account the change in the multiple scattering factor $f$, defined as the ratio between primary scattering and multiple scattering, i.e.,

$L=f L_{a}^{0}=f \frac{\tau_{a} \varpi_{0} P_{a}(\theta)}{4 \mu_{v}} \frac{E_{s}}{\pi}$,

In the MERIS ground segment, the multiple scattering factor $f$ has been implemented in the form of LUT computed with the SOS code and generated for the 26 Junge models. To derive $\tau_{a}$ with the IOPA, we need to reconstruct the aerosol path radiance. It can be done through Equation 5 with the former Junge models. But the interpretation of Eq. 5 with IOPA models requires the knowledge of $f$. It is not so simple to generate a set of new LUTs of $f$ with the IOPA models. We choose, according to some hypothesis, to use $f$ implemented in the MERIS ground segment with the IOPA models. The main hypothesis that we made is that $f$ is the same for two families of aerosol models. To validate this hypothesis, we simulated $f$ with the SOS code for two different families of aerosol models, the Junge models and the Shettle and Fenn (1979) models corresponding to the same $\alpha$. In Fig. 9, we plotted $f$ at $870 \mathrm{~nm}$ for three classes of aerosol models (coastal, maritime and rural) with a relative humidity of $50 \%$. The solar zenith angle was set to $70^{\circ}$ and $\tau_{a}$ was set to 0.15 . As we can see, there is no big difference between the two families, particularly as to the rural model between $110^{\circ}$ and $150^{\circ}$ of $\theta$. The comparison of the new $\tau_{a}$ with the IOPA models is reported in Fig. 10. The quality of the linear regression is slightly improved; with a slope of 1.01 for IOPA models and 1.05 with the Junge models (Fig. 3b). These changes are not considered to be significant.

4.3.2 The MERIS 1st processing with IOPA model: deriving $\alpha$ and $\tau_{a}$ in the blue

In this part we explored the possibility to return to the 1 st processing with the IOPA models. Starting from the aerosol path radiance in the blue, we used the $\alpha$ derived from MERIS and its associated IOPA models that give the $\omega_{0} P_{a}$ to derive $\tau_{a}$ in the blue. With $\alpha$, we obtained $\tau_{a}$ in the red. That is the 1 st processing and its associated $\tau_{a}$ values. Then, we reconstructed the aerosol path radiance in the red as we did in the blue. We could then vary both aerosol path radiances. So, we used the MERIS algorithm that is described as follows:

1. A double loop is done with $26 \alpha_{J}$ (26 Junge models) and with $\tau_{a}$ to retrieve the aerosol path radiance. Outputs are 26 values of $\tau_{a}$.

2. This double loop is applied in the blue and in the red. The resulting $\tau_{a}$ are reported in Fig. 11 . 
(a)

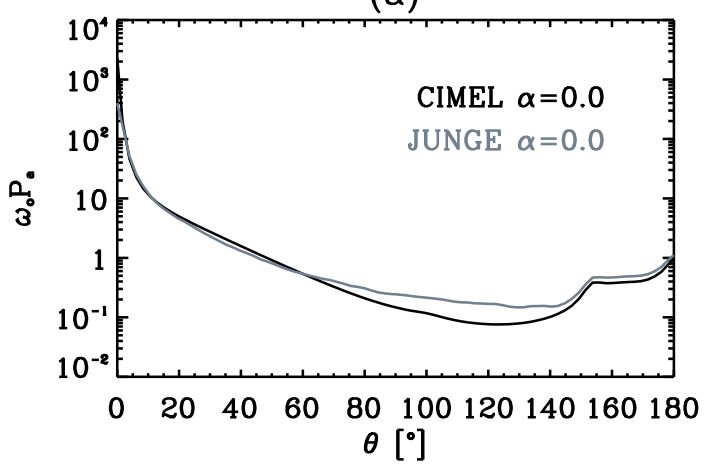

(c)

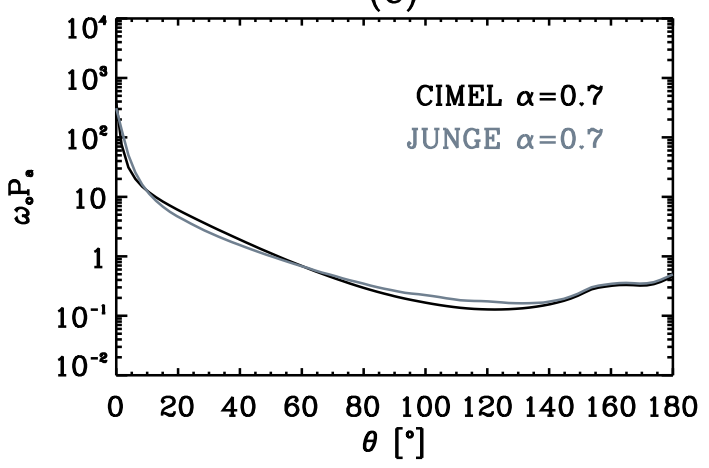

(e)

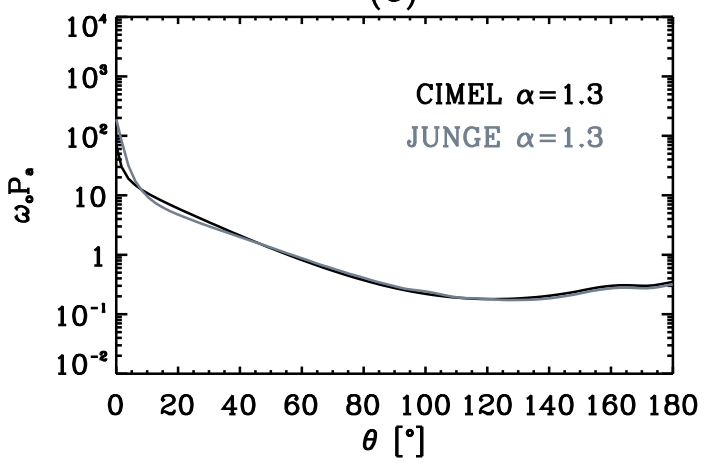

(g)

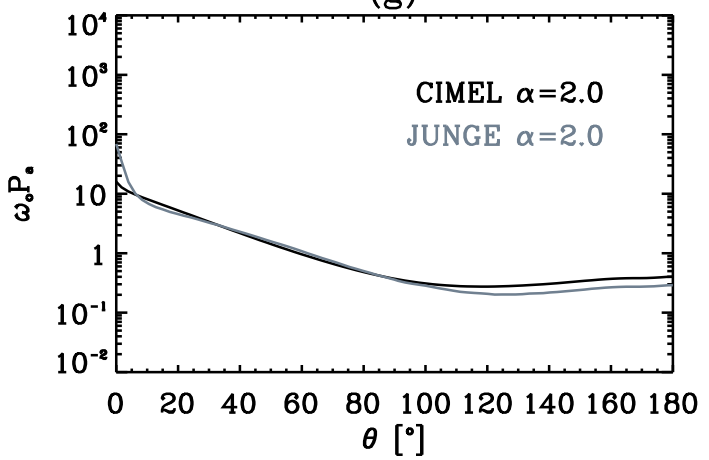

(b)

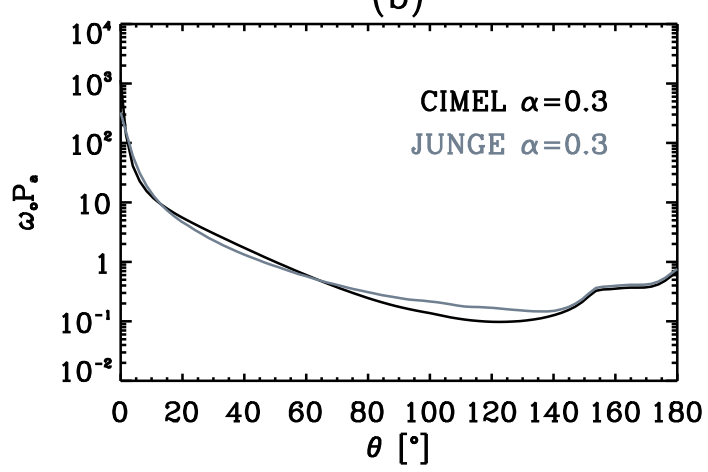

(d)

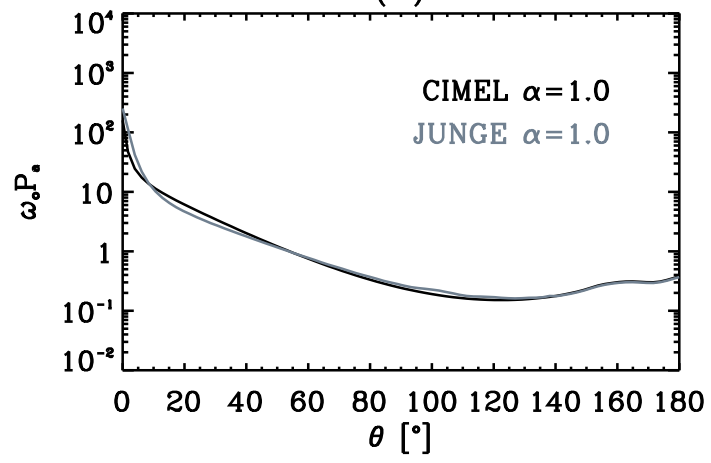

(f)

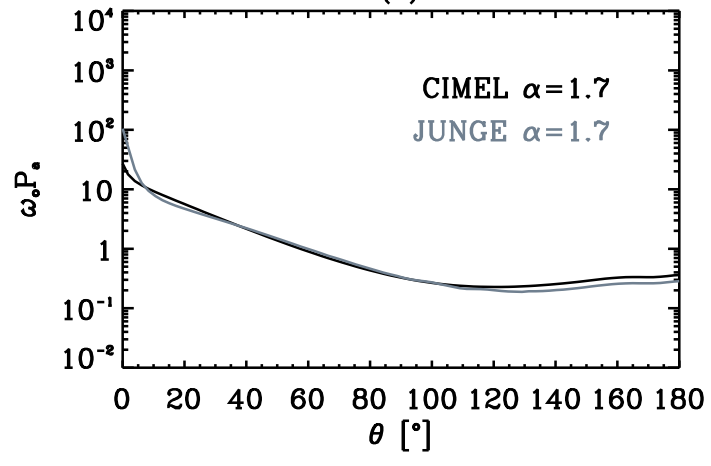

(h)

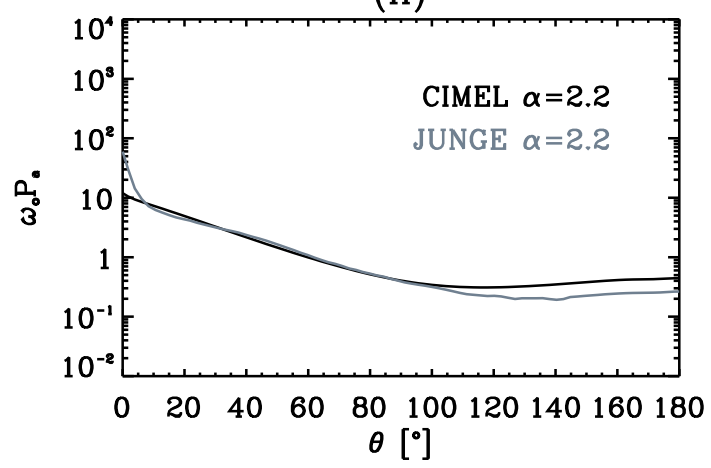

Fig. 8. Comparison on $\omega_{0} P_{a}$ versus the scattering angle $\theta$ between the initial values using the Junge models and the retrieved values from CIMEL sky measurements. Results are reported for different values of $\alpha$ (from a to $\mathbf{h}$ ). 


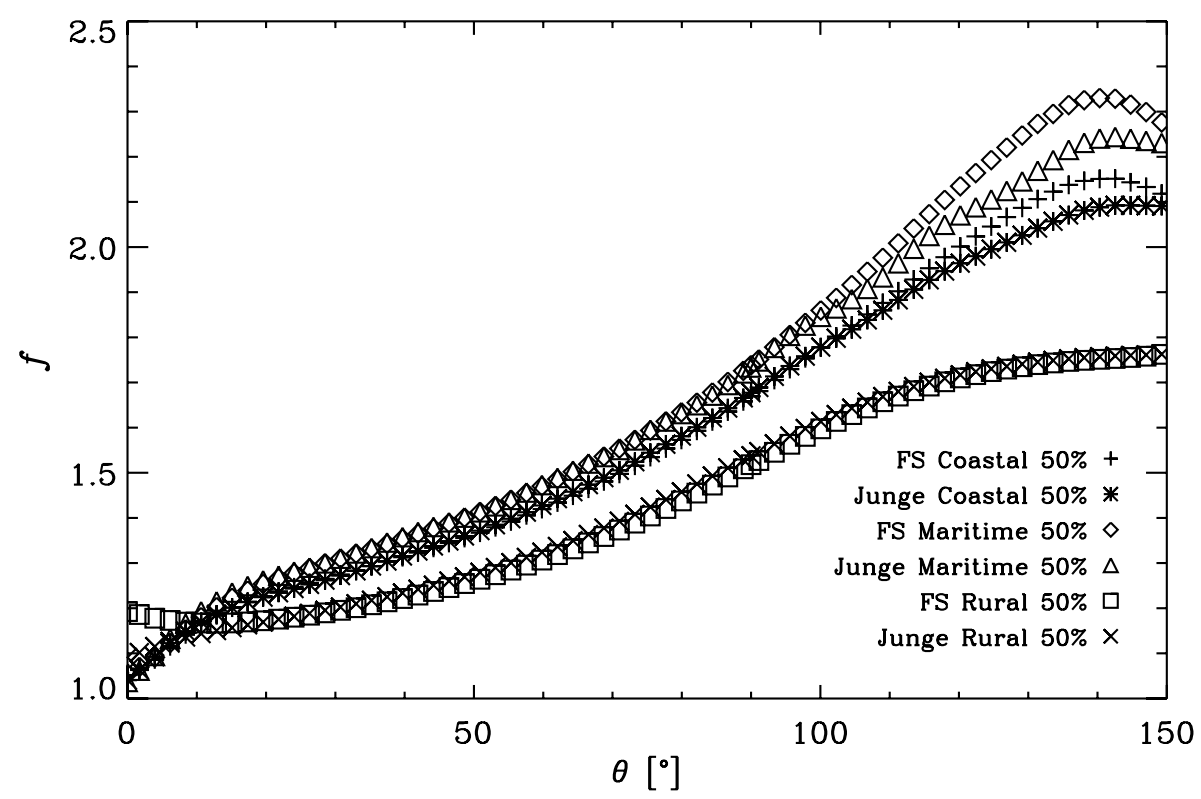

Fig. 9. Multiple scattering factor $f$ at $870 \mathrm{~nm}$ versus the scattering angle $\theta$ calculated for two different aerosol families (Junge models and Fenn and Shettle (FS) models) and for three aerosol types (coastal, maritime and rural) with a relative humidity of $50 \%$.

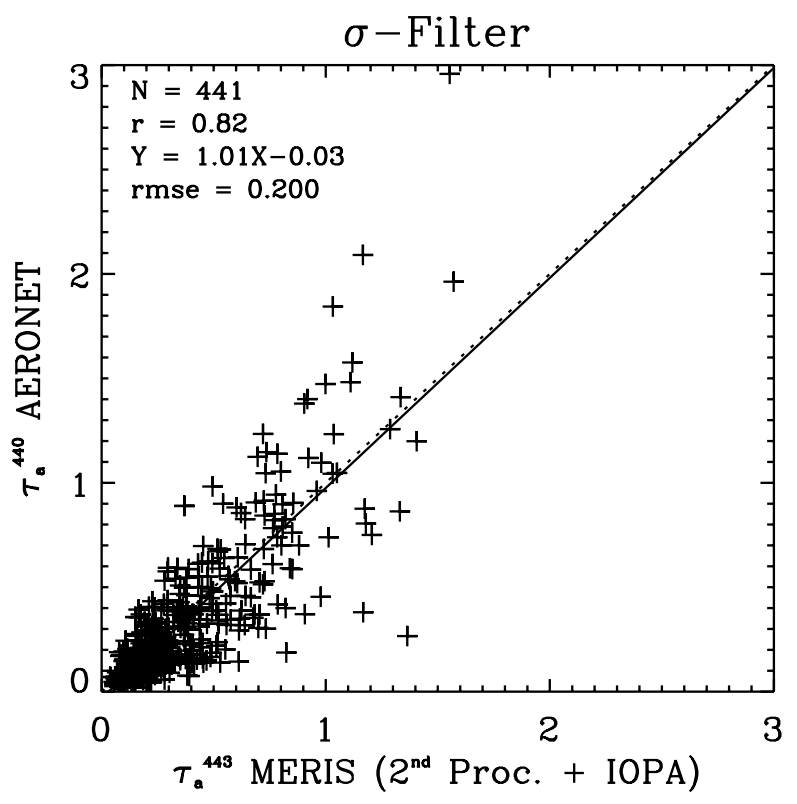

Fig. 10. Scatterplot of $\tau_{a}$ AERONET versus 2nd processing $\tau_{a}$ MERIS retrieved with the IOPA models in the blue for the $\sigma$-filtered match-ups.

3. From the two series of retrieved $\tau_{a}$, we compute an Angtrom coefficient $\alpha_{\text {MERIS }}$.

4. When $\alpha_{\text {MERIS }}=\alpha_{J}$, we get the final $\tau_{a}$.

Some comments about Fig. 11 are necessary. When $\alpha$ increases, $\omega_{0} P_{a}$ increases, as we can see on Fig. 7. Therefore,

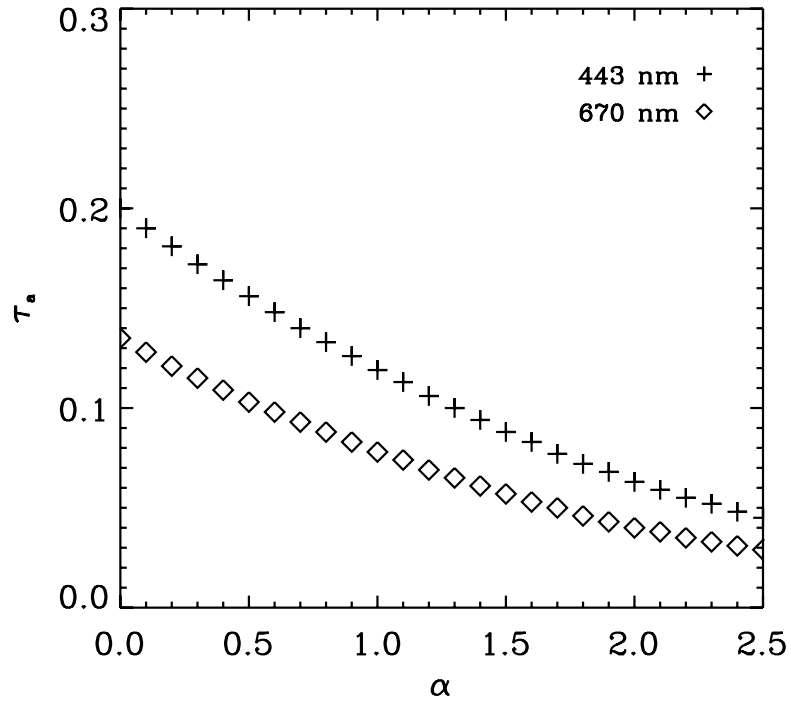

Fig. 11. $\tau_{a}$ in the blue and in the red versus $\alpha$ as obtained by the MERIS 1 st processing by looping on the 26 Junge models. These results have been obtained on the Alta Floresta AERONET site on June, 18th 2002.

$\tau_{a}$ decreases with $\alpha$ in proportion with $\omega_{0} P_{a}$ in the primary scattering approximation (Eq. 3), and it does a little more when accounting from the multiple scatterings. Because the aerosol phase function has no wavelength dependency, the $\tau_{a}$ ratio $443 / 670$ is insensitive to $\alpha$, if we exclude the second order effect of the multiple scattering. We can now apply the MERIS first processing with IOPA models. Figure 12 illustrates the comparison of $\tau_{a}$ in the blue (left panel) and in 
(a)

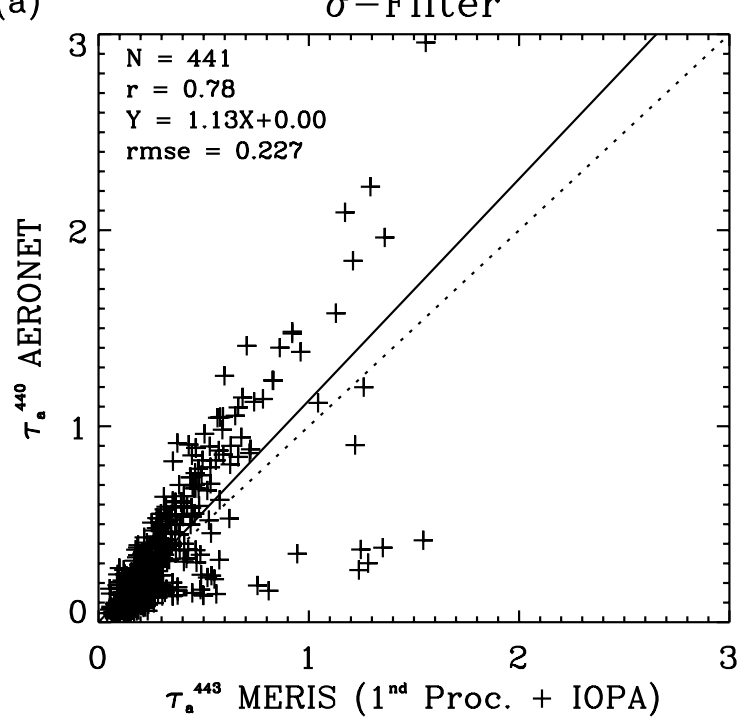

(b)

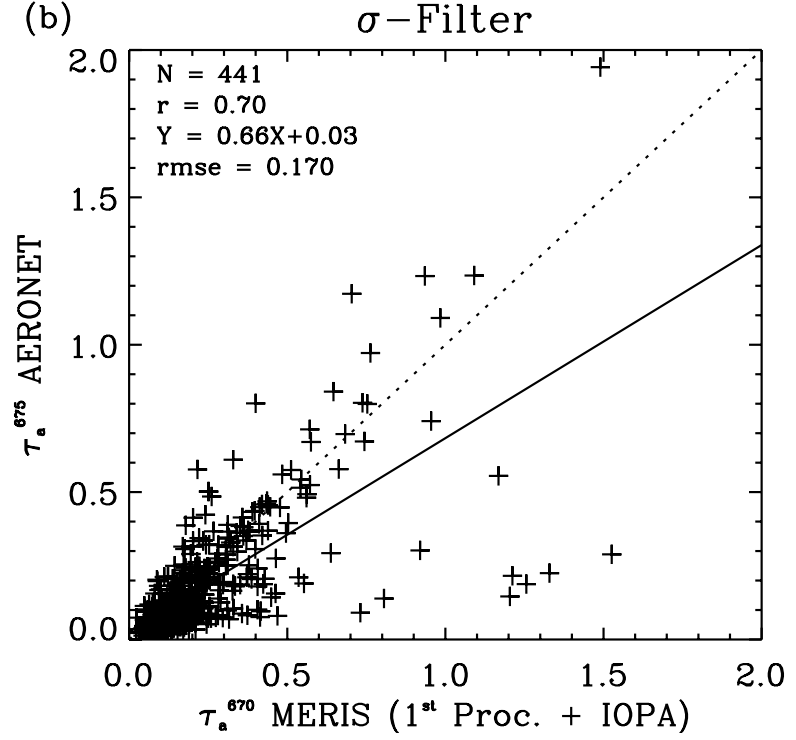

Fig. 12. Scatterplot of $\tau_{a}$ AERONET versus 1st processing $\tau_{a}$ MERIS retrieved with the IOPA models in the blue (a) and in the red (b) for the $\sigma$-filtered match-ups.
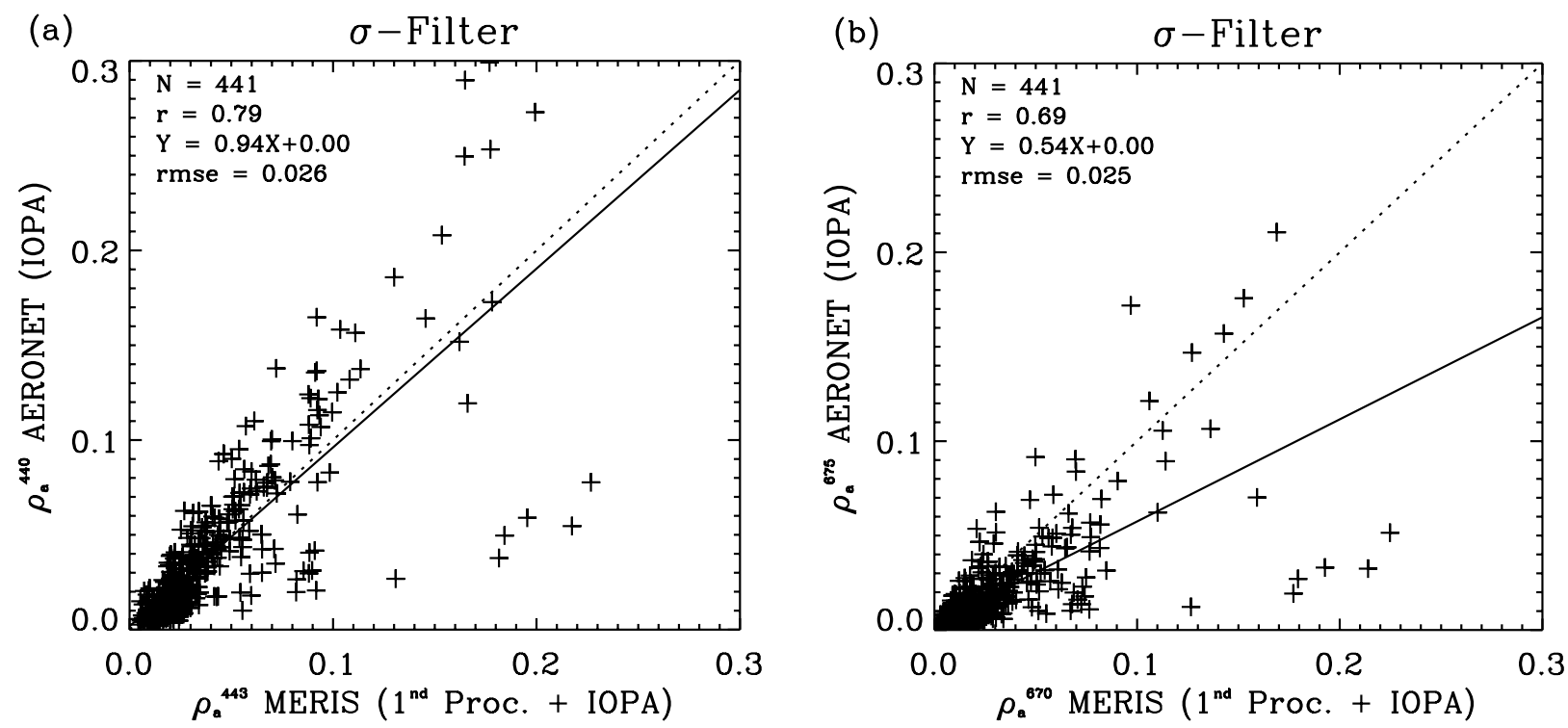

Fig. 13. Scatterplot of AERONET aerosol reflectance versus 1st processing MERIS aerosol reflectance recalculated with the IOPA models in the blue (a) and in the red (b) for the $\sigma$-filtered match-ups.

the red (right panel) with the AERONET outputs. Introducing the IOPA models into the MERIS 1st processing leads to a slight increase of the correlation coefficient in the blue from 0.72 (Junge models) to 0.78 (IOPA) and a decreasing of the rmse from 0.271 to 0.227 , respectively. However, the 2nd processing with IOPA gives better results at least in the blue (Table 4). In the red, we still have an overestimation of $\tau_{a}$ compared to AERONET.

\subsection{Possible errors in the LARS reflectance at $670 \mathrm{~nm}$ ?}

With the aerosol models, the other key parameter in the MERIS $\tau_{a}$ retrieval over land is the knowledge of the LARS surface reflectance. We expect that an inaccuracy in the LARS surface reflectance has less impact on the $\tau_{a}$ retrieval in the blue when compared to the red for the following reasons: (i) vegetation appears darker in the blue than in the red 
Table 4. Summary of the statistical outputs from the scatterplots applied on the $\sigma$-filtered match-ups for the different cases studied here.

\begin{tabular}{lccrc|rrrr}
\hline & \multicolumn{3}{c}{ blue } & \multicolumn{4}{c}{ red } \\
case & $r$ & Slope & Intercept & rmse & $r$ & Slope & Intercept & rmse \\
\hline 1st proc./Junge models & 0.72 & 0.73 & 0.05 & 0.271 & - & - & - & - \\
2nd proc./Junge models & 0.83 & 1.05 & -0.04 & 0.200 & 0.73 & 0.62 & 0 & 0.196 \\
1st proc./IOPA models & 0.78 & 1.13 & 0 & 0.227 & 0.70 & 0.66 & 0.03 & 0.170 \\
2nd proc./IOPA models & 0.82 & 1.01 & -0.03 & 0.200 & - & - & - & - \\
2nd proc./IOPA models & 0.84 & 1.00 & 0.01 & 0.190 & - & - & - & - \\
+ corrected LARS & & & & & & & & \\
\hline
\end{tabular}

and (ii) the aerosol signal increases towards the blue. It is clearly the case from the above results (Table 4). To effectively demonstrate this, let us assume that the aerosol type is known. First, let us take $\alpha$ as measured by AERONET. If we have the correct aerosol model with IOPA, then we should have the correct aerosol reflectance if the LARS reflectance is correct. We ran the MERIS 1st processing with the "exact" aerosol type and output the aerosol reflectance. Results are reported in Fig. 13. The retrieval in the blue is a little biased and remains bad in the red, due to the LARS reflectance. In the blue, the MERIS LARS reflectance is a little high, resulting in an under determination of $\tau_{a}$. Conversely, in the red, the MERIS LARS reflectance is too low resulting in an over determination of $\tau_{a}$. The two combined give an underestimate of $\alpha$. Now if we correct the LARS reflectance in the blue based on the underestimation of the aerosol reflectance, we are able to retrieve a new $\tau_{a}$ in the blue. Figure 14 shows the comparison of the $\tau_{a}$ AERONET versus the $\tau_{a}$ MERIS in the blue from the IOPA models and the corrected LARS reflectance. We finally obtained a slight increase of the correlation coefficient to 0.84 with a slope of the linear regression equal to 1 with a very small intercept of 0.01 .

\section{Conclusion and recommendations}

An extensive data set of CIMEL AERONET measurements was used in the evaluation of the MERIS aerosol product over land. This aerosol product consists basically in $\tau_{a}$ in the blue and in the red. There is, at first, a clear need to better filter the MERIS $\tau_{a}$ within the box selected for the comparison between MERIS and AERONET. The filtering used here was based on the spatial homogeneity of $\tau_{a}$ with a threshold on the standard deviation within the box. Artificial spatial variations of $\tau_{a}$ are commonly caused by, (i) the wrong cloud masking: it is known that cirrus clouds are badly detected and the use of the $\mathrm{O}_{2}$ A-band would be very useful, (ii) the edges of a cloud: Santer et al. (2005) noticed artificial increases of $\tau_{a}$ in the vicinity of clouds, and (iii) the shadow of the cloud: in the MERIS processing, LARS pixels in the cloud shadows are rejected by a radiometric threshold which has to be validated. One solution to overcome these difficulties is to

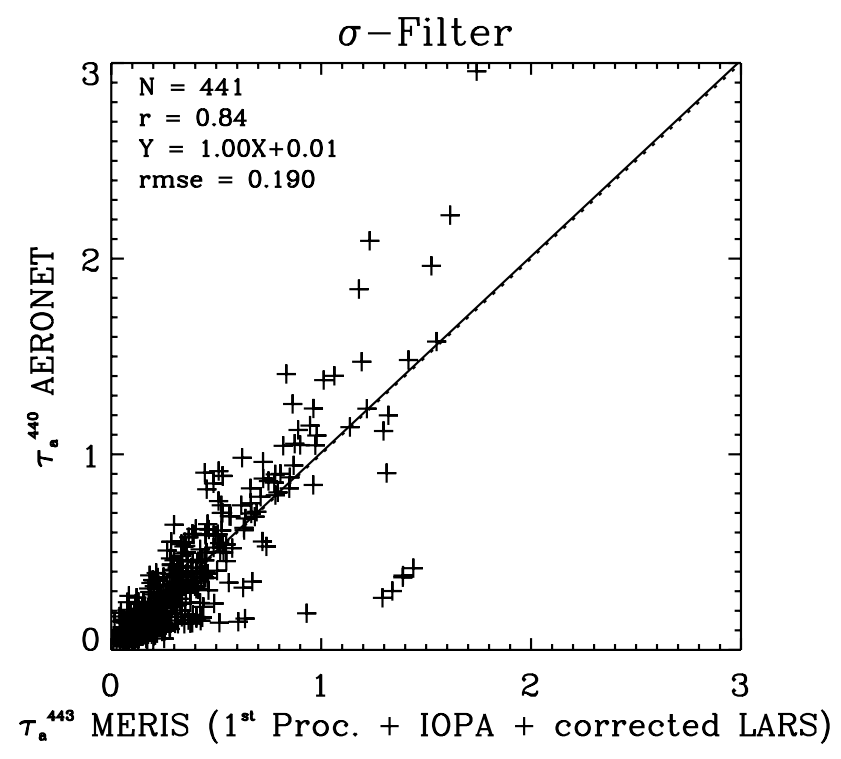

Fig. 14. Scatterplot of $\tau_{a}$ AERONET versus 1 st processing $\tau_{a}$ MERIS retrieved with the IOPA models and the corrected LARS surface reflectance in the blue for the $\sigma$-filtered match-ups.

supervise the selection of the validation points. This painful process will reduce the number of validation points. Clearly a validation of the aerosol product has to be conducted on a daily level 3 product. This level 3 product should be elaborated taking into account the different origins of the biases in the $\tau_{a}$ retrieval.

After a simple data filtering (based on a threshold of 0.15 on the standard deviation of $\tau_{a}$ in the blue over the $10 \times 10$ pixels box), the first conclusion is that MERIS correctly estimates $\tau_{a}$ in the blue compared to AERONET with a regression equation of $y=1.05 \times-0.04$ and a correlation coefficient of 0.83 . The application of this filter is recommended to any given user who wants to use the data because we found that the filter reduced the rmse from 0.215 to 0.2 in the blue and from 0.217 to 0.196 in the red. However, $\alpha$ is clearly strongly underestimated. By spectral extrapolation, we can imagine the disaster for $\tau_{a}$ at $865 \mathrm{~nm}$, which is the standard product over ocean, and then on the homogeneity between water-land products. The reference in $\tau_{a}$ in the blue 
is therefore relevant.

The reconstruction of the 1st processing on LARS pixels instead of DDV pixels indicates that it is better to arbitrary set $\alpha$ to 1 . It justifies the choice made for the 2 nd processing which allows to propose a better spatial coverage of the aerosol product combined to a reliable estimate of $\tau_{a}$ in the blue. Furthermore, we found that the rmse is reduced from 0.271 for the 1 st processing to 0.2 for the 2 nd processing showing that the current version of the MERIS aerosol product over land is the most appropriate.

The choice of a Junge models to describe the aerosol optical properties was quite arbitrary. It was sustained by the simplification in the LUT generation due to the non dependence of the aerosol phase function with wavelength. It did not pretend to describe the microphysical properties of the aerosol by their inherent optical properties.

Using alternative aerosol models based on the CIMEL sky radiance measurements at AERONET sites, the IOPA models, confirms that the main improvement necessary concerns the LARS surface reflectance in the red. At present time, the LARS surface reflectance LUTs were produced by the MODIS surface albedo map. Alternatively, we can also use the MERIS surface albedo map (Schroeder et al., 2005). It remains that the production of albedo maps requires to apply atmospheric correction, therefore knowing $\tau_{a}$. This infernal loop is broken if the albedo maps are only produced for clear days, which is difficult to obtain globally.

One alternative to avoid the difficulty in the red is to evaluate the performance of using the couple $(412 \mathrm{~nm}-490 \mathrm{~nm})$ instead of $(443 \mathrm{~nm}-670 \mathrm{~nm})$. A negative result of the aforementioned alternative is the reduced spectral interval. On a positive note, though, is that the LARS reflectance at $490 \mathrm{~nm}$ is slightly darker than at $670 \mathrm{~nm}$. Moreover, the linear dependency of the LARS reflectance at $490 \mathrm{~nm}$ versus the ARVI is less pronounced than at $670 \mathrm{~nm}$. It is foreseen to use the MERIS prototype to test alternative LUTs of LARS reflectance as well as to combine $412 \mathrm{~nm}$ and $490 \mathrm{~nm}$ on these AERONET match-ups.

Acknowledgements. We first want to thank all the PI's for their effort in establishing and maintaining the different CIMEL instruments that we used in the AERONET network. We then thank Didier Ramon (from the HYGEOS company) for fruitfull discussions. This work was supported by the European Space Agency (ESA/ESRIN) in the frame of MERIS support activities and by partially funded by the Programme National de Télédétection Spatiale (PNTS) from the Centre National d'Etudes Spatiales (CNES).

Edited by: J. Quaas

\section{References}

Abdou, W. A., Diner, D. J., Martonchik, J. V., Bruegge, C. J., Kahn, R. A., Gaitley, B. J., Crean, K. A., Remer, L. A., and Holben,
B.: Comparison of coincident Multiangle Imaging Spectroradiometer and Moderate Resolution Imaging Spectroradiometer aerosol optical depths over land and ocean scenes containing Aerosol Robotic Network sites, J. Geophys. Res., 110, D10S07, doi:10.1029/2004JD004693, 2005.

Aznay, O. and Santer, R.: Validation of the La Crau aerosol model using the Avignon AERONET site, internal report, LISE-ULCO, 2007.

Bokoyé, A. I., Royer, A., O’Neill, N. T., and McArthur, L. J. B.: A North American Arctic Aerosol Climatology using GroundBased Sunphotometry, Arctic, 5, 215-228, 2002.

Chin, M., Ginoux, P., Kinne, S., Torres, O., Holben, B. N., Duncan, B. N., Martin, R. V., Logan, J. A., Higurashi, A., and Nakajima, T.: Tropospheric Aerosol Optical Thickness from the GOCART Model and Comparisons with Satellite and Sun Photometer Measurements, J. Atmos. Sci., 59, 461-483, 2002.

Delwart, S., Bourg, L., and Huot, J.-P.: MERIS $1^{\text {st }}$ year: early calibration results, in: Proceeding of SPIE in Sensors, Systems and Next-Generation Satellite VII, Barcelona (SPAIN), 8-12, September 2003, 5234, 379-390, 2003.

Deuzé, J.-L., Herman, M., and Santer, R.: Fourier series expansion of the transfer equation in the atmosphere-ocean system, J. Quant. Spectrosc. Ra., 41, 483-494, 1989.

Deuzé, J.-L., Bréon, F.-M., Devaux, C., Goloub, P., Herman, M., Lafrance, B., Maignan, F., Marchand, A., Nadaf, L., Perry, G., and Tanré, D.: Remote sensing of aerosols over land surfaces from POLDER-ADEOS 1 Polarized measurements, J. Geophys. Res., 106(D5), 4913-4926, 2001.

Dubovik, O., Smirnov, A., Holben, B. N., King, M. D., Kaufman, Y. J., Eck, T. F., and Slutsker, I.: Accuracy assessments of aerosol optical properties retrieved from Aerosol Robotic Network (AERONET) Sun and sky radiance measurements, J. Geophys. Res., 105, 9791-9806, doi:10.1029/2000JD900040, 2000.

Dubovik, O., Holben, B., Eck, T. F., Smirnov, A., Kaufman, Y. J., King, M. D., Tanré, D., and Slutsker, I.: Variability of Absorption and Optical Properties of Key Aerosol Types Observed in Worldwide Locations, J. Atmos. Sci., 59, 590-608, 2002.

Eck, T. F., Holben, B. N., Ward, D. E., Dubovik, O., Reid, J. S., Smirnov, A., Mukelabai, M. M., Hsu, N. C., O’Neill, N. T., and Slutsker, I.: Characterization of the optical properties of biomass burning aerosols in Zambia during the 1997 ZIBBEE field campaign, J. Geophys. Res., 106, 3425-3448, doi:10.1029/2000JD900555, 2001.

Eck, T. F., Holben, B. N., Dubovik, O., Smirnov, A., Goloub, P., Chen, H. B., Chatenet, B., Gomes, L., Zhang, X. Y., Tsay, S. C., Ji, Q., Giles, D. and Slutsker, I.: Columnar aerosol optical properties at AERONET sites in central eastern Asia and aerosol transport to the tropical mid-Pacific, J. Geophys. Res., 110, D06202, doi:10.1029/2004JD005274, 2005.

Grey, W. M. F., North, P. R. J., Los, S. O., and Mitchell, R. M.: Aerosol optical depth and land surface reflectance from multiangle AATSR measurements: global validation and intersensor comparisons, IEEE T. Geosci. Remote Sens., 44, 2184-2197, doi: 10.1109/TGRS.2006.872079, 2006.

Holben, B. N., Eck, T. F., Slutsker, I., Tanré, D., Buis, J. P., Setzer, A., Vermote, E., Reagan, J. A., Kaufman, Y. J., Nakajima, T., Lavenu, F., Jankowiak, I., and Smirnov, A.: AERONET - A Federated Instrument Network and Data Archive for Aerosol, Remote Sens. Environ., 66, 1-16, doi:10.1016/S0034- 
4257(98)00031-5, 1998.

Hsu, N. C., Tsay, S. C., King, M. D., and Herman, J. R.: Deep blue retrievals of Asian aerosol properties during ACE-Asia, IEEE Trans. Geosci. Remote Sens., 44, 3180-3195, 2006.

Intergovernmental Panel on Climate Change, 2007, Climate Change 2007: The Scientific Basis, 996 pp., available on http://ipcc-wg1. ucar.edu/wg1/wg1-report.html, 2007.

Kahn, R. A., Gaitley, B. J., Martonchik, J. V., Diner, D. J., Crean, K. A. and, Holben, B.: Multiangle Imaging Spectroradiometer (MISR) global aerosol optical depth validation based on 2 years of coincident Aerosol Robotic Network (AERONET) observations, J. Geophys. Res., 110, D10S04, doi:10.1029/2004JD004706, 2005.

Kaufman, Y. J. and Sendra, C.: Algorithm for automatic atmospheric corrections to visible and near-IR satellite imagery, Int. J. Remote Sens., 9, 1357-1381, 1988.

Kaufman, Y. J. and Tanré, D.: Atmospherically resistant vegetation index (ARVI) for EOS-MODIS, IEEE T. Geosci. Remote, 30, 261-270, doi:10.1109/36.134076, 1992.

Kaufman, Y. J., Tanré, D., Remer, L. A., Vermote, E. F., Chu, A., and Holben, B. N.: Operational remote sensing of tropospheric aerosol over land from EOS moderate resolution imaging spectroradiometer, J. Geophys. Res., 102, 17051-17068, doi:10.1029/96JD03988, 1997.

Kaufman, Y. J., Tanré, D., and Boucher, O.: A satellite view of aerosols in the climate system, Nature, 419, 215-223, 2002.

Kneubuehler, M., Schaepman, M. E., Thome, K. J., and Schlapfer, D. R.: MERIS/ENVISAT vicarious calibration over land, in: Proceedings of SPIE, Sensors, Systems, and Next-Generation Satellites VII, edited by: Meynart, R., Neeck, S. P., Shimoda, H., Lurie, J. B., and Aten, M. L., 5234, 614-623, 2004.

Levy, R. C., Remer, L., Mattoo, S., Vermote, E., and Kaufman, Y. J.: Second-generation algorithm for retrieving aerosol properties over land from MODIS spectral reflectance, J. Geophys. Res., 112, D13211, doi:10.1029/2006JD007811, 2007.

Mishchenko, M. I., Cairns, B., Hansen, J. E., Travis, L. D., Burg, R., Kaufman, Y. J., Martins, V., and Shettle, E. P.: Monitoring of aerosol forcing of climate from space: analysis of measurement requirements, J. Quant. Spectrosc. Ra., 88, 149-161, 2004.

Moody, E. G., King, M. D., Platnick, S., Schaaf, C. B., and Feng, G.: Spatially complete global spectral surface albedos: value-added datasets derived from Terra MODIS land products, IEEE T. Geosci. Remote, 43, 144-158, doi:10.1109/TGRS.2004.838359, 2005.

Preusker, R. and Fischer, J.: Cloud top pressure retrieval within the O2-A band with the satellite sensors MOS and MERIS, in: Proceedings of the International Geoscience and remote sensing Symposium (IGARSS'99), Hamburg, Germany, 28 June-2 July 1999 (Piscataway, New Jersey: IEEE), 1999.

Ramon, D. and Santer, R.: Operational Remote Sensing of Aerosols over Land to Account for Directional Effects, Appl. Optics, 40, 3060-3075, 2001.

Ramon, D., Santer, R., and Dubuisson, P.: MERIS surface pressure and cloud flag: Present status and improvements, in: Proceedings of the Envisat Validation Workshop 2002, 9-13 December 2002, ESRIN Frascati, Italy, 2002.

Ramon, D., Santer, R., Dilligeard, E., Jolivet, D., and Vidot, J.: Validation of MERIS products over land, in: Proccedings of the MERIS Users Workshop, ESA ESRIN, 10-13 November 2003,
Frascati, Italy, 2003.

Ramon, D. and Santer, R.: Aerosol over Land with MERIS, Present and Future, in: Proceeding of the MERIS and AATSR Workshop 2005, ESA SP-597, 26-30 September 2005, ESRIN, Frascati, Italy, 2005.

Rast, M. and Bezy, J. L.: The ESA Medium Resolution Imaging Spectrometer MERIS a review of the instrument and its mission, Int. J. Remote Sens., 20, 1681-1702, doi:10.1080/014311699212416, 1999.

Remer, L. A., Kaufman, Y. J., Tanré, D., Mattoo, S., Chu, D. A., Martins, J. V., Li, R. R., Ichoku, C., Levy, R. C., Kleidman, R. G., Eck, T. F., Vermote, E., and Holben, B. N.: The MODIS Aerosol Algorithm, Products, and Validation, J. Atmos. Sci., 62, 947-973, 2005.

Santer, R., Carrère, V., Dubuisson, P., and Roger, J. C.: Atmospheric correction over land for MERIS, Int. J. Remote Sens., 20, 1819-1840, doi:10.1080/014311699212506, 1999.

Santer, R. and Martiny, N.: Sky radiance measurements for ocean colour calibration-validation, Appl. Optics, 42, 896-907, 2003.

Santer, R. and Lemire, F.: Validation of the MERIS Atmospheric Corrections: Toward a New Aerosol Climatology, in: Proceeding of the ENVISAT workshop, Salzburg, 6-10 September 2004, Austria, 2004.

Santer, R., Ramon, D., Vidot, J., and Dilligeard E.: A surface reflectance model for aerosol remote sensing over land, Int. J. Remote Sens., 28, 737-760, doi:10.1080/01431160600821028, 2007a.

Santer R., Zagolski F., and Aznay, O.: Iterative process to derive aerosol phase function from CIMEL measurements, Int. J. Remote Sens., submitted, September 2007, 2007b.

Schafer, J. S., Eck, T. F., Holben, B. N., Artaxo, P., Yamasoe, M. A., and Procopio, A. S.: Observed reductions of total solar irradiance by biomass-burning aerosols in the Brazilian Amazon and Zambian Savanna, Geophys. Res. Lett., 29, 4-1, doi:10.1029/2001GL014309, 2002.

Schroeder, T., Fischer, J., Preusker, R., Schaale, M., and Regner, P.: Retrieval of Surface Reflectance in the Framework of the MERIS Global Land Surface Albedo Maps Project, in: Proceeding of the MERIS and (A)ATSR Workshop 2005 (ESA SP-597), 26-30 September 2005, ESRIN, Frascati, Italy, 2005.

Shettle, E. P. and Fenn, R.W.: Models fort he aerosols of the lower atmosphere and the effects of humifity variations on their optical properties, Air Force Geophysical Laboratory, Technical Report AFGL-TR-79-0214, Hanscom Air Force Base (Mass.), 1979.

Smirnov, A., Holben, B. N., Eck, T. F., Dubovik, O., and Slutsker, I.: Cloud-Screening and Quality Control Algorithms for the AERONET Database, Remote Sens. Environ., 73, 337-349, doi:10.1016/S0034-4257(00)00109-7, 2000.

Toledano, C., Cachorro, V., Berjon, A., Sorribas, M., Vergaz, R., De Frutos, A., Anton, M., and Gausa M.: Aerosol optical depth at ALOMAR Observatory (Andøya, Norway) in summer 2002 and 2003, Tellus B, 58, 218-228, doi:10.1111/j.16000889.2006.00184.x, 2006.

Wilson, R. and Sprengler, J. D.: Particles in our air: concentrations and health effects, Harvard University Press, 259 pp., 1996.

Zagolski F., Santer, R., and Aznay, O.: A new climatology for atmospheric correction based on the aerosol inherent optical properties, J. Geophys. Res., 112, D14208, doi:10.1029/2006JD007496, 2007. 